\title{
CATARACT EXTRACTION
}

\section{FROM THE POINT OF VIEW OF THE GENERAL PRACTITIONER.}

By Colonel R. H. Elliot, M.D., F.R.C.S.

(Contd. from page 325.)

\section{The Decision as to the time for an Extraction.}

Having broken to a patient that he has a cataract, the next point for consideration is that of the time when an extraction should be undertaken. I know that the advice usually given is that a patient must wait for complete maturity before undergoing operation and that if he has good sight in the other eye he should wait on until this also fails him. With such advice I am in the strongest disagreement. I do not ask you to take my opinion instead of that of others, but I will give you the grounds on which I have formed it and will leave you to make your own decisions.

One cannot lay down precise rules as to when a cataract should be operated on, but one can take all the factors of each individual case into consideration and then give one's opinion after weighing the pros. and cons. We have to think of the patient's age, his prospect of life, the state of his general health, the condition of the second eye, the nature of the cataract, the amount of vision he possesses, the rate of the progressive failure of vision, any past history of eye trouble which may have left a damaged retina, and of each and every other factor with which we can make ourselves acquainted.

Are we justified in saying to a man, "your right eye sees well, and though your left is cataractous, I do not advise you to have it touched?" My answer is an emphatic negative, and for the following reasons:-

(I) A man who is blind on one side is exposed to many inconveniences and to many risks. You have only to have one of your eyes shut up for a few days in order to realise how true this is, and if it is true in the prime of life, how much more must it be of elderly people? I have known quite a number of such meet with serious accidents. They run into lamp-posts or other obstacles; they knock up against people on the pavement and thereby excite indignation instead of getting the sympathy which they really deserve; they are knocked down when crossing the road for want of seeing on-coming vehicles; and their greatest danger of all is from careless tradesboys and cyclists. It will be argued that you cannot fit up an aphakic eye with a suitable lens and so make it work in double harness with the other which has hitherto been unoperated. This is freely admitted, but does not affect the argument. Once the lens has been extracted, the patient can see moving objects on that side very readily and quickly, and can also distinguish the presence of large stationary objects. He is thus in the position to turn his good eye in the necessary direction and so to get a clear view, which is a great source of protection to him. $\mathrm{He}$ is much safer in the streets or even in the house, and this is reflected in his comfort and happiness. I am not talking theoretically, for many patients have told me that this is so; and no one can say that such considerations are unimportant.

(2) The question of morale comes in. One of the most trying elements in operations for cataract is the fact that the patient must lie for one or two days in the dark after the lens has been removed. Another is that some weeks or even months must elapse between the extraction and the happy time when, fitted with glasses, the patient is enabled to see really well again. Let us take these points in order. 
During the long hours whilst the patient is lying in the dark, his mind is for ever turning over and over the chances of success and the risks of failure. With the thought of those risks comes the terrible realisation of all that failure means to his future and to those dependent on him. If he still has sight in the other eye, the prospect of possible disappointment, black as it may seem, is not so terrifying and annihilating for he can console himself with the thought, "Anyway I still have the other eye to get on with." It may be that the vision of it is steadily failing, but immediate total blindness has not to be faced, and that counts for a great deal. It is much easier to meet troubles for which we have a little time to prepare and which we can persuade ourselves may never eventuate. I hope you will not think I am stressing this matter unduly. I am sure that I am not doing so. I have talked to many of these people, and I have tried to put myself in their place for the moment and to see things as they are seeing them. I feel sure that there are few factors which help us more than the establishment of a quiet, confident frame of mind in our cataract patients. I make a point of opening the second eye as early as I can, especially in the very old-sometimes at the end of twenty-four hoursand I go out of my way to encourage them to look forward to the release of this eye from the very start. "We will be able to give you the good eye to see with tomorrow," is a sentence that alters the patient's whole outlook on life. It is not merely the relief from the tedium of constant darkness that helps him, but the feeling that he is treading on firm earth again. I speak metaphorically and yet with very real meaning. The ophthalmic patient is so different from the man who has had a severe surgical operation which makes him feel too ill to take an interest in his condition. In the case of one of our patients the mind is clear and alert, and is apt to be feverishly active. He thinks and thinks and thinks; he has only too much time to do so. The result often is that he lives in a waking nightmare. Open the other eye and he at once gets courage and confidence; he is back at least where he was before the operation. The world has become real again; he has his feet on earth once more, as soon as he has the other eye to see with.

(3) Cataract operations are practically always performed on elderly people, and we must not forget that so far as health and resistance are concerned, such people go downhill much faster than the young or even than the middle-aged. It is a commonplace of medical experience that a fall or other injury, a stroke, an attack of 'flu or of any severe illness, or even a great sorrow or cause for anxiety may profoundly affect the health of an elderly person and just make the difference between his being a good subject for operation or a very bad one. The opportunity once lost may never return, with the result that the man is condemned to permanent blindness. All the interest is thus taken out of his life and he sinks to the level of a human cabbage, a burden to himself and to all about him. We are all familiar with the phrase "he was never the same man again." Though hackneyed, it embodies an important clinical fact.

Apart altogether from disease, every year of life after a certain period lessens a patient's resistance to any shock, be it operation, injury or illness. It is true that much more depends on the vital characteristics of the individual than on the actual number of years he or she has lived. We meet among our patients with men and women who are old and worn out at fifty-five. Others are taking an active part in life, are playing games and hunting at sixty or seventy. A few of the most robust are still going strong at eighty and even at ninety or more. I once extracted a cataract from an old man on his ninetieth birthday and he continued to play golf thereafter. Nevertheless, every year counts as life advances. The same man is a 
better subject at seventy than at seventy-one, and still more so at eighty than at eighty-one. If his prospects of life are good, the earlier we operate the better chance we give him of a happy and useful old age.

(4) With the modern methods of operating any lens can be safely removed however immature the cataract that darkens its vision. The idea widely prevalent among the public, and even among a large section of the medical profession, that it is necessary to wait for maturity before extracting a cataract, is quite erroneous. It is true that more care is required and that convalescence may be lengthened owing to the need to allow the cortex which has been left behind to become absorbed; but provided the operation is skilfully and aseptically carried out, the added risks are so slight as to be negligible. They are certainly not worth weighing against the very serious disadvantage of allowing an elderly person to drop the activities of a lifetime with the risk that he or she will never take them up again. It is so much easier for the old to drop their habits than to resume them after a period of inaction. Few things are more tragic than to look on helplessly at the decay of everything which once endeared a man or woman to his friends and relatives.

(5) The hypermaturity of a cataract brings definite risks in its train. This fact is much more familiar to those who have worked in India than to their European colleagues for the simple reason that in the West very few cataracts are allowed to become hypermature, whilst in the East a very large percentage of the cases fail to present themselves until a very late stage has been reached. Many years ago I visited the Zurich Clinic, and Professor Haab who was kindness and courtesy itself and who showed me all the wonders of his hospital and school-wonders which I did not delay to imitate at the earliest possible date in India-but submitted me to a long cross-examination on cataract before he took me round at all. $\mathrm{He}$ put it politely that in this way I was to pay my footing. After asking me many questions he showed me a model of a Morgagnian cataract and wanted to know if I had ever seen one. When I told him that about thirty per cent. of our cataracts in an Indian Clinic were Morgagnian he took me for a relative of Baron Von Munchausen, and yet I was only stating a fact that could be borne out by a study of the statistics of any big Indian eye hospital. It is the old story of "The Pasha of Many Tales" who was intensely interested in the description one of his subjects gave him of his swim from India to England and of his enforced stoppage at the Cape to scrape off the barnacles that were impeding his progress. When the unfortunate man, being asked to dine with His Highness, saw him partaking of capers and ventured to say he had seen them growing on a tree, the enraged Pasha, who had only met capers in a bottle, said, "The man is a liar, off with his head." In India we see the results of allowing cataract to proceed to hypermaturity. In Madras we found that about three per cent. of hypermature cataracts developed secondary glaucoma, and we also met at times with a slow form of iritis in these over-ripe lenses. I admit freely that such complications are much more rarely met with in England for the simple reason that so few cases are allowed to become hypermature, but the danger is a real one and its presence cannot be denied. The risk of glaucoma is greatest in those swelling cataracts which have a white shiny appearance, which often present mother-of-pearl sectors and which are associated with a shallow anterior chamber owing to the bulging forward of the swollen lens. All the same, the onset of glaucoma cannot always be excluded in the cases with a brown cataract, especially if it is associated with a shallow chamber. Do not forget that once a patient has developed glaucoma or iritis, the prospects of a good result are seriously prejudiced, though, if the cases are taken promptly in hand, brilliant results may sometimes be 
obtained. I therefore hold most firmly that unless there is some strong contraindication in the state of the patient's health, every cataract should be removed as soon as it is mature and none should ever be allowed to go on to hypermaturity.

I have given you my reasons for disagreeing most strongly with the opinion that so long as one eye sees well the cataract in the other should be left untouched. It is up to you to weigh the evidence carefully and to form your own decisions.

\section{The Operation on the Second Eye.}

I come now to another very important question, namely, that of the operation on the second eye. When a patient has a good result in one eye should he have the other one operated on or not? The answer generally given to this question in England is in the negative. I cannot agree with this and I have no hestitation in saying that, unless there is some strong contraindication, the extraction of the second cataract should be proceeded with as soon as maturity is reached. Once again, I will give you my reasons for this opinion. To some extent they necessarily overlap those already given in discussing the preceding question.

(I) I have already in that discussion pointed out to you the risks that a man runs who is blind on one side. These are not less, but rather greater when the opposite eye is aphakic for the simple reason that even with the best cataract glass and with a vision straight ahead of $6 / 5$ or even $6 / 4$, the width of the field is narrower than with a normal eye. This is largely a question of the limitations imposed by the strong glasses needed after the removal of the lens. With a narrower field a patient is obviously slower in picking up an object. It is thereforea imperative that he should get all the warning possible. Even an uncorrected eye? is helpful in enabling him to sight things, whereas when both eyes are fitted with glasses he attains the maximum safety possible for him in his aphakic condition.

(2) The question of the future of the eye first operated on must be taken into careful account. However excellent the result of the extraction may be, the sight of the eye may subsequently be lost in a variety of ways. Injury, retinal hamorrhage, central retinitis, glaucoma and a host of other evils lie in wait for the old patient, and the cataract patient is almost invariably old. One cannot afford to take any risks where sight is concerned for its value is too great. I go further and make it a principle of life never to sacrifice even the smallest remnant of sight if I can help it. The opinion is sometimes given " the sight of that eye is so poor and that of the other is so good that it is hardly worth while worrying about the worse eye." Not once, but many, many times, have I seen the good eye fail and the patient forced to rely on what in old days he spoke of as an almost useless eye. The small measure of vision which he thought of so lightly has now come to be his mainstay and the comfort of his last years. The difference between total blindness and even the small measure of sight which enables a man to find his way round his own house and garden or down the village street is immense. Unless there is some strong contraindication, I urge every cataract patient to make his margin of safety as wide as possible and to have the second eye operated on at an early date.

(3) Closely connected with the matters discussed in the previous paragraph is the question of morale. When the first eye has been successfully operated and the patient feels, that barring the totally unforeseen, useful vision is assured him for the rest of his life, he will approach an operation on the second eye with quiet confidence, and the wait in darkness after the operation will be easily and stoically 
borne. If, on the contrary, anything has happened to the eye from which the first cataract was removed, necessitating an operation on the second for the recovery of useful sight, things are far otherwise. He feels he has reached his last line of defence; everything depends on the extraction, and even if it is successful, there is the haunting spectre that this eye may go the way the previous one did and that all his efforts may end in disappointment. It is quite true that in the great majority of cases an eye successfully operated for cataract maintains vision indefinitely, but there are exceptions and most surgeons have met with such at one time or another. One patient whom I vainly urged to have his cataract extracted from the second eye developed diabetes many years afterwards, with severe hæmorrhages in the operated eye. In another a blow on the good eye caused a retinal detachment. In a third an overripe cataract led to secondary glaucoma on the unoperated side. There have been other cases of the same kind. Not many I admit when put against an experience of many thousands of extractions, but few as they have been, they have stamped their lesson on my mind by their tragedy and by the melancholy fact that the disasters might have been so easily avoided.

(4) The attainment of binocular vision is a very great advantage to any patient. Not only does it greatly widen his field and thus add to his safety as he goes about the world, but it increases the acuity of his central vision. Any of you who have tested an ordinary patient for refraction will know that if, for instance, you can get him $6 / 6$ in each eye separately he will read one or possibly two lines better than this with the two eyes together, and this whether with the naked eyes or with a suitable correction for any errors in refraction that may be present. The same thing is true of hearing or of the sense of smell. You can easily test the former by listening to a uniform sound such as the music of a gramophone or a voice on the wireless, and alternatively plugging one ear with a finger or leaving both ears open. The difference is most striking. I have frequently found that after operating on the second eye, the patient's vision, both for near and far distance, is materially improved although the second eye may have given no better results than the first. I need not dilate on the advantages of stereoscopic vision. Very many patients have commented enthusiastically on the improvement in their condition after the second eye has been brought into play.

(5) Quite a number of patients complain of coloured vision after an extraction. By far the most frequent colour is blue. As a rule this passes quickly away and excites but little comment from the patient, but sometimes it is persistent and causes the sufferer a good deal of anxiety. I have known it continue for many months after the first extraction and in these cases have noted that the nucleus of the second lens was of a yellow or brown colour. The cyanopsia has, in my experience, always disappeared after the extraction of the second lens. When, many years ago, I described this blue-vision as a frequent sequel of cataract extraction in India, I was told that it was never met with in this country. My experience over here has shown me that it is nearly, if not quite, as frequent in London as it is in Madras. If it is enquired for in a routine manner this observation will, I am sure, be confirmed.

(6) Once again, the question of the patient's resistance comes up, and all I had to say when justifying my contention that if one eye only is cataractous it should be operated on as soon as it is ripe applies here again, only with more force because, on the average, the patient on whom an operation is called for in the second eye is older than the other. Every year counts and the sooner the extraction can be performed the better. This statement requires some qualification. Where both eyes contain 
mature cataracts I think that as a rule they should be operated on with about a fortnight's interval between the two extractions. In Madras the rule was a week, but there we had pressure on our beds to consider and a very heavy cataract list to get through. The advantage of a fortnight is that it gives the second eye time to become thoroughly normal again after its two or three days of enforced closure following the first operation.

Much more commonly in England, one cataract is more mature than the other, and the delay of a year or more between the two gives the patient time to pull himself together again and get over the shock of the operation.

You will understand that I am necessarily speaking in general terms. All the factors of each individual case must be taken into account before coming to a decision. It would be obviously wrong to operate on an old patient who has probably only a short time to live, especially if he has been severely tried by the first extraction. Again, if the patient's health is very poor and if the first operation has given him reasonable vision, it would be bad surgery to do anything further. You have accomplished your object of ridding him of his blindness and you may well be content with that. The successful practice of medicine is largely a question of common sense. I would leave it there.

\section{The Most Favourable time of Year for Cataract Operation.}

Once again, let me remind you that most of our cataract patients are elderly if not old. Winter is the season when colds-in-the-head, 'flu, bronchitis and pneumonia are prevalent, with all their attendant risks of secondary infection of the operation-wound and of damage to the eye by straining from coughing. It is also the time when vitality is at its lowest ebb in the old-the very antithesis of the conditions which we regard as most favourable for any operative procedure. I therefore endeavour to do all my cataract work between the Ist of April and the middle of November. I do not say that one should never operate for cataract in the winter, for exceptional cases arise. When a patient has come a long distance for the express purpose of having his cataract removed it would be unpractical to send him back again over a journey of thousands of miles to return in the summer. When, however, I have to operate in the winter I ask the patient to come into the Nursing Home one or preferably two days before the operation so as to make as sure as possible that he does not develop 'flu or a head-cold immediately after the operation. If I can have my choice I like best to operate between April and August as this gives the patient the opportunity of recuperating at the seaside in warm weather during convalescence. It also gives time for his eyes to become less sensitive before the cold weather arrives. I look upon this as an important point.

\section{The History of Duration of a Cataract.}

This is often very unreliable, especially when the trouble is bilateral. Some patients notice the very earliest beginnings of cataract and come complaining of interference with their vision; whilst in others-and in very intelligent people too -the onset of blindness is so gradual that it seems altogether to escape detection. In India where cataract is very rife, it is an everyday experience to have patients complaining of diminution of vision in the second eye without their having ever noticed that the first one has completely lost all sight. Though less common, the same experience is occasionally met with in London. Such people date the commencement of their whole trouble, not from the time when the first cataract 
began, but from that when the second had advanced sufficiently to cause inconvenience. It is important from the point of view of prognosis to ascertain within as small a margin as possible the times when the cataracts in the two eyes commenced. Sometimes the evidence of other surgeons who have examined the patient may be very valuable; but remember that cataract, especially when peripheral or again when merely a nuclear haze, is not infrequently overlooked, even on ophthalmoscopic examination. These details are insisted on because, if from time to time the eyes are carefully and methodically examined and the results noted, we have the best possible guide as to the rate at which the affection is progressing. At the same time, you must remember that cataracts are like weeds ; they sometimes go slow for a long time and then suddenly take on rapid growth, or vice versa.

Occasionally patients with a nuclear haze will complain of haloes strongly suggestive of glaucoma. I have followed several such cases for long periods and convinced myself that they were not suffering from an increase in intra-ocular pressure. The obvious inference appeared to be that the haloes were the result of the lens haze.

\section{The Anæsthetic Used.}

One of the first questions one is asked is whether a general anæsthetic will be given, and people are as a rule greatly relieved to learn that the operation is performed under local anæsthesia and that they may rest assured that they will have no pain at the time, though there may be some headache coming on within half an hour of the operation and lasting for five or six hours; this is seldom severe and is sometimes quite negligible. If there is much complaint of pain, ro grains of aspirin will almost always give relief. Local anæsthesia has two great advantages: (I) The patient can be of much assistance to the surgeon by looking down when asked to do so, and thus exposing the operation area well and readily; and (2) The danger of post-operative vomiting is eliminated. There is another point on which it is well to reassure the patient: he often has the idea that the slightest movement on his part will cause the operation to fail. This is quite erroneous, for a skilful surgeon can finish an extraction successfully, even with a nervous and troublesome patient. I met with many such in Madras where self-control is much less developed than it is in London, but even out there the factor did not cause serious inconvenience. Moreover, the very people who most fear that they will give the surgeon trouble are among the best we have. Women as a rule behave better than men, and " the nervous lady" often earns on her notes a comment as to her great steadiness. I never fail to make a record as to a patient's behaviour under operation for it may prove a valuable guide on later occasions.

\section{The Prospect of a Good Result after Operation.}

Strange as it may seem, it is very far from infrequent for a patient or his friends to ask "Can you promise a good result?" I have known cases in which such a result was actually promised, to the patient's bitter disappointment. It would seem obvious to anyone that nothing is certain in life and that any man who makes such promises stands self-condemned. It is quite a different thing for a surgeon to give an intelligent forecast of the probabilities, and this he may fairly do. The operation for cataract is today a very safe one, provided that the cases are carefully selected and that every precaution is taken to exclude sepsis, both from the surface and from the interior of the body beforehand. It is an 
easy matter to sterilise our instruments, our hands and all that comes near the patient. A course of silver collosol drops for a fortnight before the operation and the use of a I/3000 perchloride of mercury ointment placed in the conjunctival sac night and morning for the last three or four days makes the conjunctiva safe for a preliminary iridectomy, always provided that there is no evidence of congestion or inflammation present there. For the final extraction operation, however, I always advise a week's course of silver nitrate drops (gr.3, aqua destill. ad oz.I) to be used once daily. It is true it is a painful remedy, and many patients and their doctors will write in alarm about the congestion produced. I can speak at first hand of the pain, for when I was unlucky enough to get an attack of granular ophthalmia in Madras many years ago, I had not 3 but ro gr. to the ounce, not dropped in, but rubbed in daily for six weeks. I have never forgotten it. The pain of the treatment I am now advising is, however, quite moderate in most cases, if the sac is well washed out immediately after the instillation; it can be controlled by cocain and hot fomentations to a great extent. On the other hand, I regard the use of silver nitrate as a most valuable guard against infection of the wound from conjunctival organisms. If patients will not persevere with it, then I take my chance with the milder treatment, but if the matter is put squarely to them and they are assured that harm never comes from the treatment, they are usually most ready to carry it out. In Madras it was the custom to use 5 and Io gr. to the ounce solutions of silver nitrate on a very large number of cases of catarrhal conjunctivitis every morning, especially during the season when ophthalmia was epidemic; I have never seen any harm come from it.

Then as to internal sepsis or auto-intoxication. We may have taken every care to see that no germs from without enter our operation wound, and yet the citadel may be betrayed from within. The two focuses of sepsis of which I am most afraid are the teeth and the nasopharynx. I deliberately put them in this order. Many dental surgeons are only too inclined to give a clean bill of health if the patient has a good biting mouth. I am suspicious of every mouth after 50 years of age and my suspicions increase in geometrical ratio with every five years added thereto. Only too often I have been told that the patient has no focus of dental sepsis although no radiogram has been taken. An opinion given in this way is utterly valueless. The issues from the point of view of the patient are too tremendous to be trifled with in this slovenly manner. I absolutely refuse to accept an opinion until an X-Ray picture has been taken and been very carefully examined. Any suspicious sepsis should be radically dealt with. The patient can get thirty-two fresh teeth, but he cannot get another eye, and it is useless to lament when it is too late. May I remind you of the lines in "Omar Khayyam."

\section{"The Moving Finger writes; and having writ, Moves on: nor all thy piety nor wit Shall lure it back to cancel half a line, Nor all thy tears wash out a word of it."}

If there is the slightest doubt, the question of the nose and throat should be carefully gone into and transillumination of the sinuses should be carried out. I would specially direct your attention to the condition of the tonsils, particularly in the rather younger cases. The very fact that the patient is supposed to have had an operation for septic tonsils may easily lull the surgeon into a sense of false security. A few small suppurating fragments left behind may be just as dangerous as the large swollen organ. I do not know what you all feel about cauterisation, guillotining and such methods, but I personally have no confidence in anything 
short of complete enucleation. I have frequently seen cases of ocular sepsis disappear entirely as soon as some fragments of tonsillar tissue which had been left behind were removed.

Any other source of suppuration in the middle ear, in the thorax or abdomen, or anywhere else, should be carefully removed before an extraction is undertaken.

Of course there are cases in which the prospects of a good result are perceptibly lessened by the presence of one or other form of unavoidable complication. It is difficult to state the increased risk numerically, but some approximation can be given by an expert. I hold most strongly that it is the surgeon's duty to put everything before the patient or his relatives and then leave the decision to them; it is very much in his own interest to do so. Whilst it is our duty to be absolutely honest with the relatives, there are occasions on which it is inadvisable to tell the patient everything, as for instance when, while an operation gives the only chance of success, the risks of failure are great. Sometimes the patient is very nervous and the relatives beg one not to tell him the whole truth, and there is very much to be said in favour of compliance with their request. If a man enters on the operation feeling that his chance is a very poor one, he is not at all likely to do well; if, on the other hand, he goes into it with his courage high, he has the best chance of success that can possibly be given him. I recently had an outstanding example of this same thing. I called in a very distinguished ophthalmic surgeon in consultation and he urged me to operate, but gave the chance as "not one per cent." I confess I thought the prospect a poor one. The friends begged that the patient might not be told this; he was encouraged to hope for a good result, and got a splendid one. I do not think he would have done so well if he had entered the undertaking without hope. Every surgeon of experience can remember similar cases.

\section{Considerations Arising from the Presence of General Disease.}

I have quite frequently been consulted by patients suffering from some form of glycosuria who have been refused operation by very able surgeons or have been told that the risks of operating in such cases are necessarily very great. In India I operated on a large number of glycosurics, many of whom were true diabetics, and with a very large percentage of success. The same has been true of similar cases that I have met with in this country. Obviously it is a prime consideration to get the patient into as good a state of health as possible before operation. So long as diacetic acid and acetone are absent and the patient is not losing weight, an extraction may be safely undertaken. To deny a hope of sight to a patient on the ground that he has sugar in his urine is unnecessary or worse. The same applies to many patients suffering from wasting and nervous diseases, and even to some of those who have had a "stroke" in the past.

A pathological tremor, even when marked and persistent, adds comparatively little to the risks of a cataract extraction when undertaken by a skilful surgeon. It does not constitute nearly so formidable a difficulty as is generally assumed.

\section{Cataract Operations in Extreme Old Age.}

It is quite a common experience to hear a patient or his friends or even his doctor, say that he is too old for operation. I have operated on a very large number of patients between 80 and 90 and on six just on 90 or over it, the oldest being 96 . On one occasion I extracted a cataract in a lady well up in the eighties, 
and many years later I operated on her son also at over 8o. Both were successful. What has struck me in these very old cases is their extraordinary stamina; they seem to stand the operation far better than many much younger people. In not one of them did the operation seem to shorten life, and many of them were very appreciative of the benefits of restored sight. The extraordinary vitality which enables people to live fifteen to twenty-five years longer than the allotted span of life, carries them successfully through the severe strain of an operation. It is worthy of note that all of them had warm hands and feet-an obvious indication of an active thermotaxic centre and of an excellent circulation. To the same factors must, I think, be attributed their unusual retention of mental powers, inclusive of memory and alertness.

\section{Continuance of Work after a Cataract Extraction.}

In the three weeks or more after the patient leaves the nursing home between the preliminary iridectomy and the extraction he can usually carry on his ordinary work, always provided that doing so does not cause pain to either eye. After the extraction he should have at least a month's rest and even then must feel his way carefully. When it is a case of using his brain and not his eye I make no objection to his directing his business as soon as he feels fit to do so, even though he may still be in the nursing home, provided that it can be done by reports read to him and by instructions taken down by a stenographer. The important thing to insist upon is that he shall hurry slowly. What he can't do today he will be able to do in a week's time or later, but he must be prepared for some amount of shock after the operation and must be made to realise that if he insists on working when he feels unfit to do so, he will probably have to pay for it later. Impress on him that his best motto is "festina lente." The amount of shock in many of the cases is altogether out of proportion to the size of the wound or to the severity of the operation, even when account is taken of the very rich nerve supply to the parts interfered with. I am quite convinced that we must attribute this shock to psychic factors. Many of the patients will say that they were not unduly anxious and will even appear quite calm and collected, but there can be no doubt that subconsciously they have worried much more than they are aware of. It is worry, not work, that kills, and the opportunity for worry and especially for subconscious worry, during the long weary hours following the operation is very great indeed. You can find an excellent illustration of this in the great tendency there is for mental wandering to manifest itself in the old whilst the eyes are shut up, and to disappear as soon as the patient is given back some measure of sight.

Then what as to the ultimate vision that one may expect after the extraction of a cataract? The straight-ahead distance vision is extraordinarily good and in a large number of cases is $6 / 5$ or better, with easy reading of diamond print. Much depends on the state of the optic nerve and retina before the operation. A number of patients continue to shoot, to play billiards, etc. Dental surgeons can carry on their very exacting work with comfort and accuracy; a specialist surgeon who works in deep cavities and for whom I have extracted both lenses, tells me that he can operate as well as ever and can pick up a bleeding vessel at the bottom of a deep hole with ease; general practitioners carry on their work without any difficulty; bankers do the same; artists seem in no way affected, except that in one case the sense of colour-values seemed to me altered, though she would not admit it. After the extraction I thought all her paintings too red. As I have already said, the field of vision is more limited than before, but this is largely a matter 
of the glasses; the patient has to develop a "rubber-neck", and many of them do so readily.

Patients will sometimes come to you with the complaint that the glasses given them by an ophthalmologist have a fixed focus. There is truth in this. Most of them-though not all-have lost all power of accommodation after the removal of the lens. It is well to explain this and to point out that to get glasses for all intermediate distances means a great addition of trouble and expense; they will wind up by having a lot of glasses tied round them like the White Knight had other property, till their possessions become a nuisance. A pair for distance and another for reading should satisfy most people, though if they want an intermediate glass for some special purpose such as music or cards, these can easily be supplied; but lay stress on the fact that one pair of glasses will only work for a special range. Luckily the distance glasses suffice for anything from twenty feet upward and are quite helpful for intermediate distances, though the sharp cut accuracy of good focus is, of course, lost. The readers should serve for most near work if the patient will bring his head down to the necessary distance.

In conclusion, I would like to say to you that to my mind, the most important advice one can give a patient after a cataract extraction is to protect his eyes for some months from chills and especially from those due to wind. I am more afraid of wind than I am of sun, dust and cold put together, and I never fail to urge on every patient the necessity of wearing efficient goggles for months after an extraction and until the eye has thoroughly settled down. In the house he can wear what he likes or rather what he finds most comfortable, but never let him go out of doors for the first few months without carrying his goggles with him and putting them on whenever he is in the slightest degree of doubt.

\section{WHAT DO WE MEAN BY RHEUMATISM? *}

By VINCENT COATES, M.C., M.A., M.D.(CANTAB.), M.R.C.P.(LOND.).

Senior Physician Royal Mineral Water Hospital, Bath.

The term "Rheumatism" is loose, indefinite and unsatisfying. "Acute Rheumatism" is applied alike to Rheumatoid Arthritis in its active phase, and to Rheumatic Fever. " Chronic Rheumatism" may imply anything between the wide ranges of generalised Fibrositis and Hypertrophic Osteoarthritis of the Hip. To remedy these defects it would seem desirable either to qualify in such a manner as to avoid ambiguity, for example, Cardiac Rheumatism and Muscular Rheumatism; or else to employ formulæ which leave no reasonable room for doubt. There is no excuse for those who claim to be teachers of the subject not to be able to mentally pigeon-hole 90 per cent. of Rheumatic or Joint Cases. It matters little what term is used to signify a given biochemical or clinical type provided that the name used denotes to the mind of the user something definite and that which he is able to describe to others by means of a cut-and-dried model. Such phrases as "Arthritis of Unclassified Origin" are definitely destructive in their appeal to searchers after the truth.

*A modified form of a lecture given at the Royal Mineral Water Hospital, Bath, on the 13th May, 1933, under the auspices of the Post-Graduate Association. 